\title{
Recurrent cholesterol embolism as a cause of fluctuating cerebral symptoms
}

\author{
W. IAN McDONALD \\ From the National Hospital, Queen Square, London
}

Embolic occlusion of a large cerebral artery commonly results in easily recognized cerebral infarction. When arterioles are involved by small emboli there may be only transient disturbances of neurological function, as, for example, when attacks of monocular blindness occur in association with recurrent retinal artery embolism (Fisher, 1959; Russell, 1961, 1963). A third, less common clinical expression of cerebral embolism is that of a fluctuating but increasing neurological deficit. The present report concerns two cases of this last kind in which multiple embolism of small arteries by cholesterol crystals was demonstrated at necropsy.

\section{CASE REPORTS}

CASE 1 A 69-year-old man (N. H. No. A16218) was admitted (Dr. William Gooddy) on 1 February 1964 with a three weeks' history of fluctuating confusion. He was known to have been hypertensive (B.P. $220 / 110 \mathrm{~mm}$. Hg) five years earlier. For four years he had been rather lethargic, and for six months he was more irritable than usual. A month before admission a biopsied enlarged axillary lymph node showed typical appearances of Hodgkin's disease (Dr. C. H. R. Knowles, St. Richard's Hospital, Chichester). Some three weeks before admission to the National Hospital he was noticed to be less mobile than usual. From this time on he showed striking fluctuations in his mental and neurological state. At times he was confused and disorientated, and there was variable and asymmetrical weakness of the limbs. He complained of difficulty with vision on several occasions. He fell on two occasions, 15 and six days before admission. Because of an increasing residual deficit he was referred to the National Hospital.

On examination he was conscious but very confused. He was completely disorientated in time and place. He was poorly cooperative, and showed marked perseveration. The fundi showed rather pale discs and moderate narrowing of the retinal arterioles; no emboli were seen but there was a fluffy exudate in the left fundus. He was able to distinguish light from dark, but was unable to fix on, follow, or identify objects. The pupils were equal, circular, and reacted to light. Spontaneous conjugate eye movements to each side were occasionally seen, and the oculo-cephalic reflexes were present but reduced in amplitude. The remainder of the cranial nerves were normal. There was marked plastic rigidity of all four limbs, more on the right and on this side there was ankle clonus and an extensor plantar reflex. The left plantar reflex was flexor. There was little spontaneous movement of the limbs, and there was moderate weakness in the legs. All the tendon reflexes, including the jaw jerk, were abnormally brisk and the abdominal reflexes were absent. Detailed sensory testing was impossible but he responded to pin prick in all areas. On general examination there were moderately enlarged firm, discrete, rubbery lymph nodes in the neck, axillae, groins, and epitrochlear regions. The liver was palpable one inch below the costal margin, but thespleen could not be felt. Blood pressure was $188 / 98 \mathrm{~mm}$. $\mathrm{Hg}$ and there was moderate cardiac enlargement. There was moderate oedema of both hands and of the left arm, and slight oedema over the sacrum and both feet, but the lung bases were clear and the jugular venous pressure was normal. The skin showed the appearances of an acquired ichthyosis or xeroderma (Dr. F. Ray Bettley).

The patient's neurological state showed quite marked fluctuations over the following three weeks but he pursued a generally downhill course. There were occasional rises of temperature to 99 or $100^{\circ} \mathrm{F}$. Three days before death he developed a persistent fever of up to $102^{\circ} \mathrm{F}$. and died three weeks after admission.

Treatment of the Hodgkin's disease had been commenced about a week after the neurological disturbance began (about three weeks before admission to the National Hospital). He was given Uracil mustard, $5 \mathrm{~g}$. daily, and Prednisone, $15 \mathrm{mg}$. daily, until he was admitted to the National Hospital, when the Uracil mustard was stopped.

Laboratory investigations (Professor J. N. Cumings) Haemoglobin $9.2 \mathrm{~g} \%$; total white blood cell count 9,600 per c.mm. (polymorphs $53 \%$, lymphocytes $7 \%$, eosinophils $40 \%$ ), E.S.R. $22 \mathrm{~mm}$. in one hour; P.C.V. $33 \%$; M.C.H.C. $28 \%$; M.C.V. 109 cubic $\mu$; R.B.C. $3,010,000$ c.mm; M.C.H. $30 \mu \mu$ g. The cerebrospinal fluid was clear and colourless and contained $35 \mathrm{mg} . \%$ of protein; no cells were seen and the Pandy, colloidal gold curve, and Wassermann reaction were normal. Total serum protein was $5.8 \mathrm{~g} \%$; the electrophoretic strip was normal. Liver function tests and serum electrolytes were normal. Blood urea $110 \mathrm{mg} \%$. Prothrombin index $84 \%$. Platelet count $179,000 /$ c.mm., clotting time 5 minutes, bleeding time $3 \frac{1}{2}$ minutes. A chest radiograph (supine) showed rounding of the left border of the heart, together with unfolding of the aorta and calcification of the 
aortic arch. An E.E.G. was taken with the patient asleep after $270 \mathrm{mg}$. of Seconal. The record was symmetrical with a background of undulating very slow waves and with bifrontal faster activity which was not clearly organized as spindles. There was very little fast rhythm such as might be attributable to Seconal. The record was slower than expected for normal light sleep, but was without localizing features (Dr. W. A. Cobb).

Necropsy findings (Professor W. Blackwood) The heart (500 g.) showed left ventricular hypertrophy. The coronary arteries were atheromatous but no occlusion was found. The striking finding in the cardiovascular system was extreme ulcerative atheroma commencing in the ascending aorta about one inch distal to its origin and continuing throughout its length. The wall of the abdominal aorta was largely calcified. The carotid arteries in the neck showed slight atheroma but no narrowing of the lumen. The basal arteries of the brain were moderately atheromatous. The renal arteries were narrowed by atheroma. The kidneys were small (left $98 \mathrm{~g}$., right 85 g.). The lymph nodes in the lung roots were slightly enlarged and oedematous but elsewhere showed no abnormality. The liver showed only nutmeg mottling. The lungs showed marked basal congestion, the left more than the right.

Microscopically the myocardium showed focal fibrosis. The kidneys showed changes of benign hypertension. There was now no evidence of Hodgkin's disease in spleen, liver or lymph nodes; the latter showed marked fibrosis.

Neuropathological findings The skull, dura, venous sinuses, and leptomeninges appeared normal. In the white matter of the cerebral hemispheres there were numerous irregular patches, a few square millimetres in area, with a purplish rim peripherally and a central region of ivory-coloured white matter. There were occasional small ragged-edged cavities in the deep and superficial white matter of the hemispheres. In the occipital regions the superior and posterior parts of the optic radiations were not easily seen. Occasional small cortical softenings were visible. The ventricles were not enlarged.

Histological examination of the brain showed that the numerous softenings in both white and grey matter corresponded with regions of ischaemic necrosis in various phases of evolution (Fig. 1). In some lesions all elements except the capillaries were absent, while in others there were numerous phagocytes (Fig. 2). Around the periphery of the lesions there were numerous reactive astrocytes. No astrocytes with the large, bizarre nuclei found in progressive multifocal leuco-encephalopathy were found (Richardson, 1961). There was slight myelin degeneration in the pyramidal tracts. Small foci of Purkinje cell and granule cell loss with astrocytic scarring were present in the cerebellum.

The interesting and unusual finding in this case was that numerous small cerebral arteries were occluded by material which in paraffin sections contained needle-like clefts (Fig. 2, ariow). Examination of unstained frozen sections showed that the clefts contained anisotropic material (Fig. 3a and 3b) which was shown by the Schultze reaction to be cholesterol. The response in the vessels to the presence of cholesterol varied. In some no

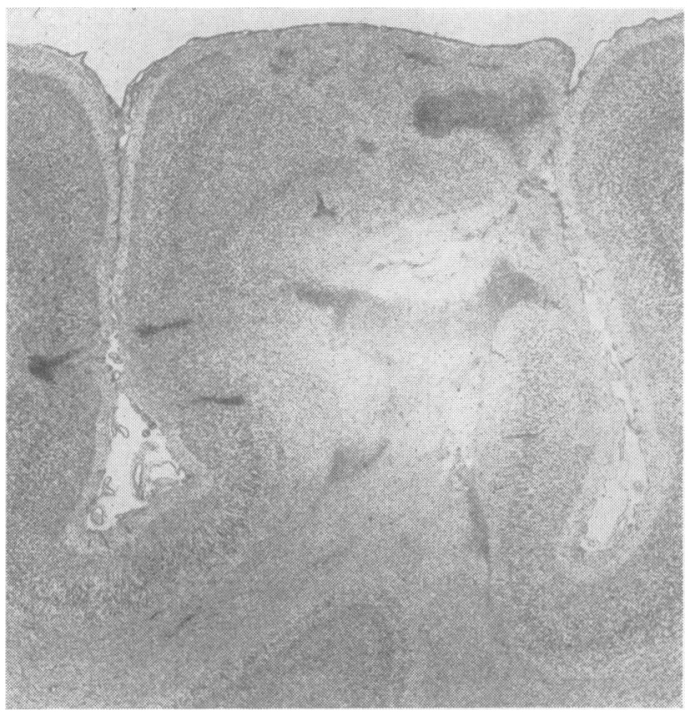

FIG. 1. Case 1. Coronal section of occipital pole showing numerous small regions of infarction. Nissl $\times 8$.

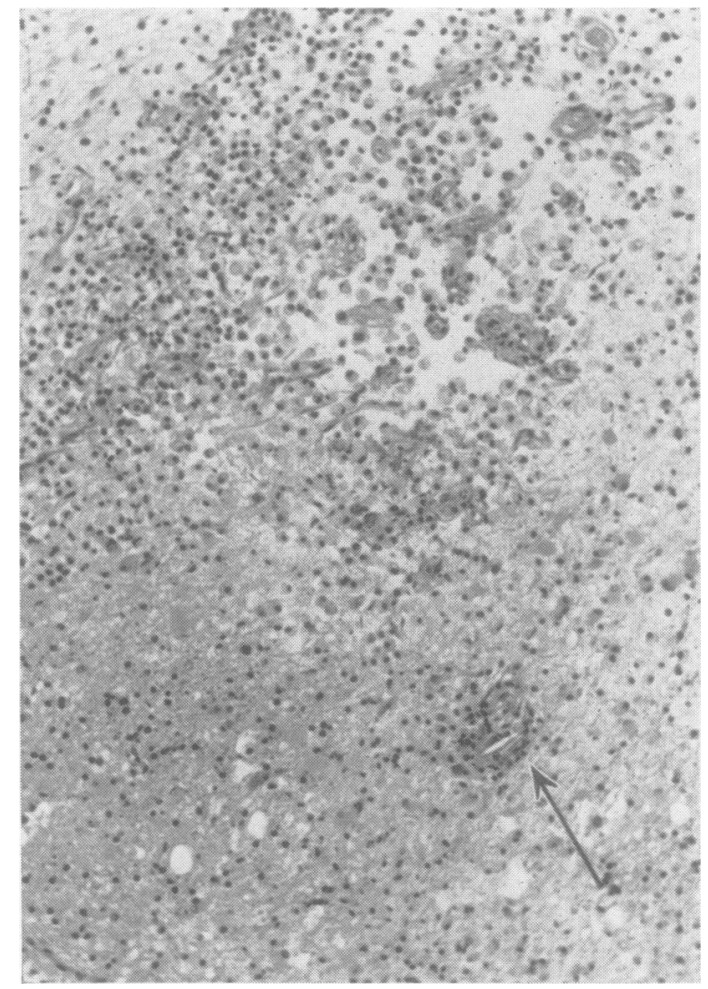

FIG. 2. Case 1. Cerebral white matter showing part of a small infarct. The arrow indicates an occluded arteriole containing cholesterol clefts. H.V.G. $\times 100$. 


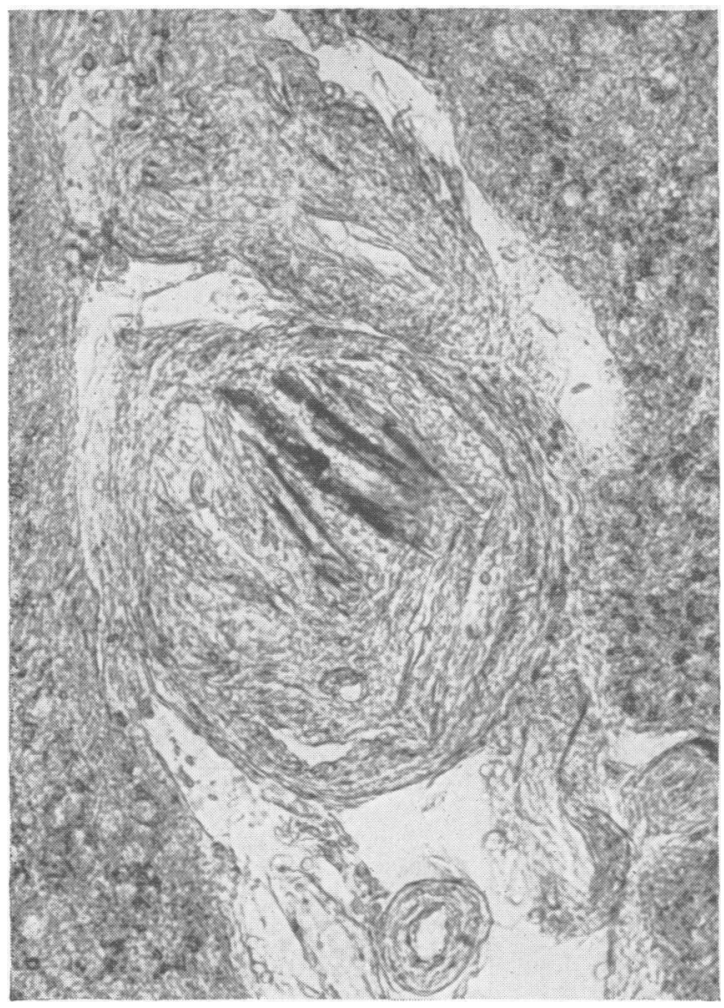

FIG. 3a. Case 1. Unstained frozen section of a small meningeal artery in a cerebral cortical sulcus. $\times 180$.

reaction at all was seen (Fig. 4). In others, multinucleate giant cells were found in relation to the clefts (Fig. 5) with varying degrees of fibroblastic reaction. The lumen of affected arteries was frequently greatly diminished or obliterated. Arteries plugged with cholesterol were often seen in the leptomeninges overlying regions of the hemisphere containing infarcts, or in the substance of the brain nearby (Fig. 2). The walls of many cortical arteries and arterioles were hypertrophic. Some larger arteries showed considerable eccentric intimal fibrosis, and there was atheromatous narrowing of the basilar artery at the level of the pons.

The right eye was examined histologically by Professor Norman Ashton. There was peripheral cystic degeneration of the retina and arteriosclerotic changes in the vessels. Some sections showed localized areas of oedema in the stratum opticum with a loss of ganglion cells. No evidence of cholesterol within the vessels was found. Outside the nervous system, in the kidneys, occasional arteries were found plugged with cholesterol.

CASE 2 A 59-year-old man (N.H. No. 24452) was admitted on 26 June 1950 (Dr. E. A. Carmichael), because of intermittent weakness of the right hand for one month, and episodic speech disturbance for one

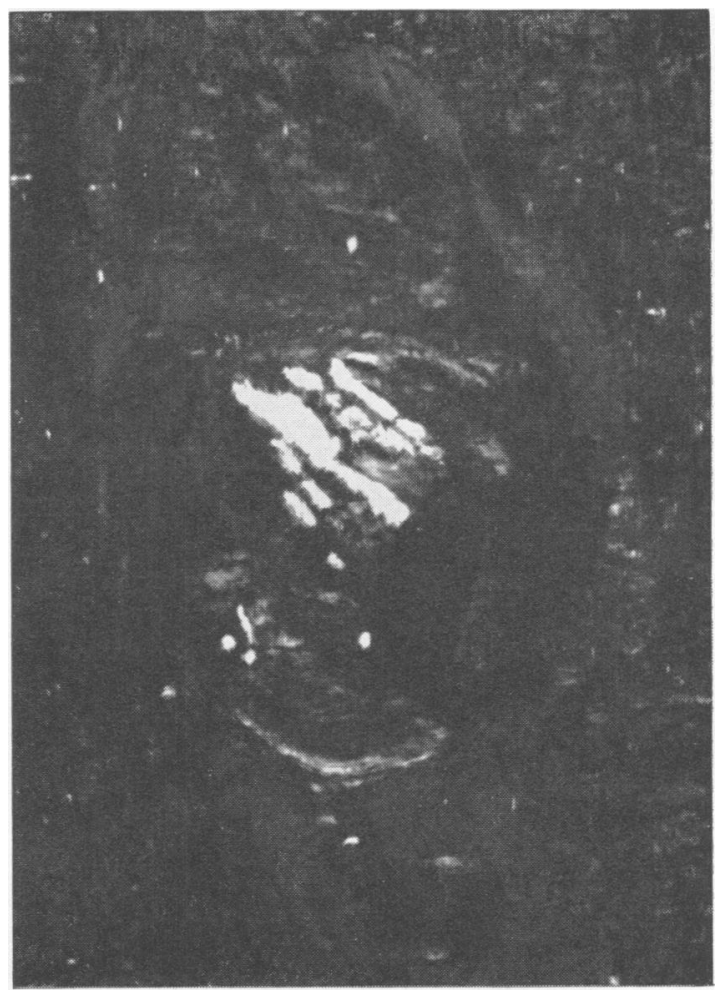

FIG. 3b. The same section as in Fig. 3a photographed with illumination through crossed polaroids.

week. A month before admission the patient woke one morning and noticed numbness in the right hand followed by paraesthesiae in the right middle, ring, and little fingers and along the ulnar side of that arm. He had difficulty with fine movements of the right hand. Next day he had a transient episode of twitching of the right side of the face, and later the numbness in the hand and arm increased; he had several episodes of paraesthesiae in the same region, each lasting a few minutes. The same day he noticed an unusual feeling in the right side of the tongue. From the onset of the illness he had had difficulty in finding words when writing or speaking. A week after the onset he had an episode of difficulty in writing. The next day the right hand was definitely weak. Eleven days after the onset of the illness, he was seen as an outpatient at the National Hospital. At that time he had a slight right facial weakness and definite weakness of the right hand. The tendon reflexes were increased in the right arm. Awareness of position of the right arm and hand in space was defective, and there was astereognosis in the right hand. Over the next two and a half weeks he had several attacks of twitching of the right side of the face. He fell on three occasions. Six days before admission he was completely unable to speak for an hour. His concentration deteriorated and his reading became very 


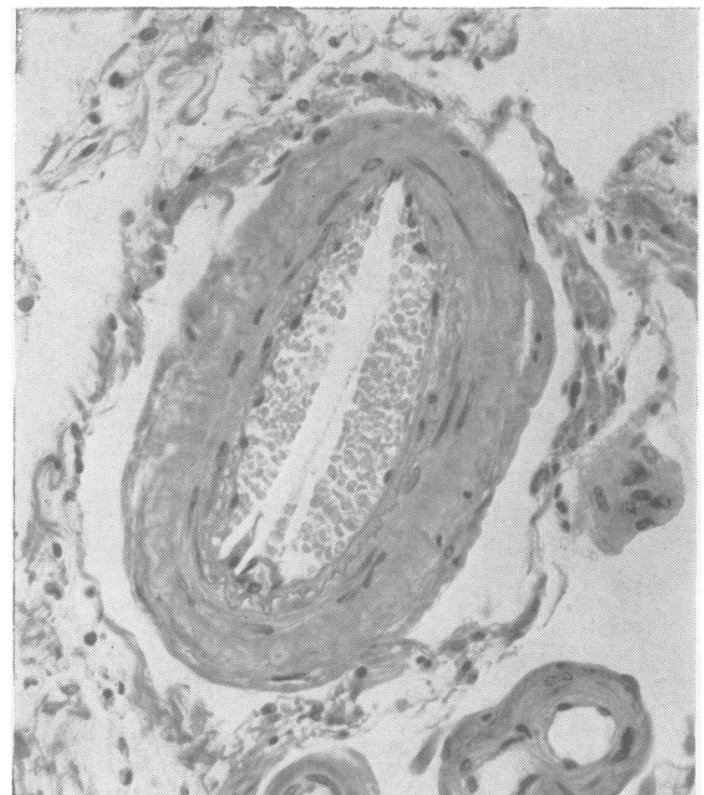

FIG. 4. Case 1. Meningeal artery containing a cholesterol cleft. The vessel is still patent. H.V.G. $\times 250$.

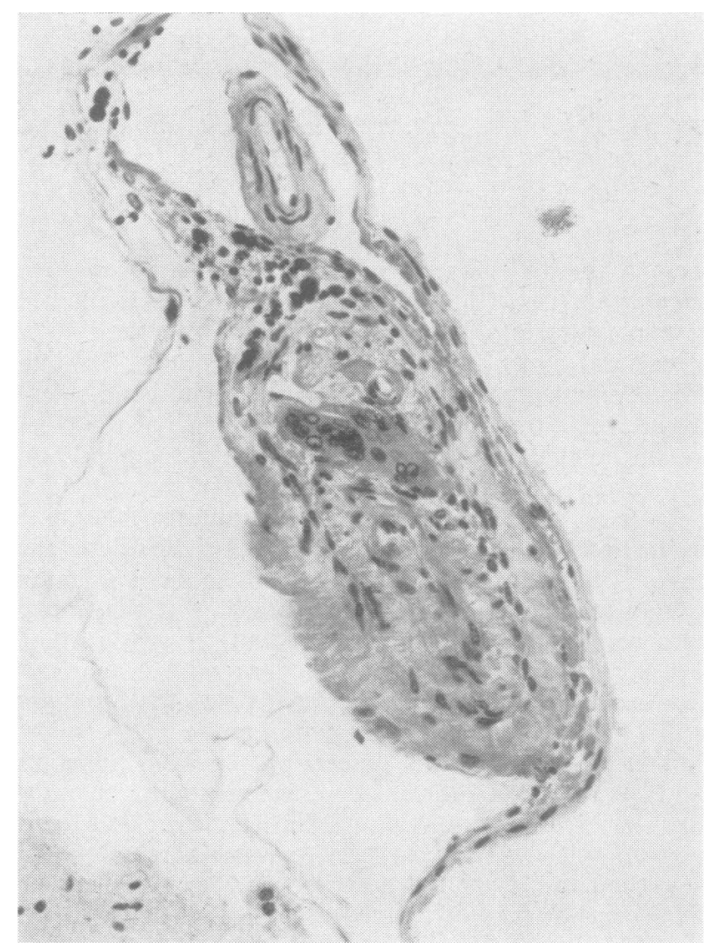

FIG. 5. Case 1. Fibroblastic proliferation and giant cell formation in a meningeal artery. H.V.G. $\times 176$. slow. Weakness of the right hand increased. The day before admission he had an episode of paraesthesiae in the right face and numbness in the right hand. On the day of admission he was barely able to speak at all.

Examination revealed a marked global dysphasia. The visual fields were full to confrontation. The retinal arterioles were narrowed, but the veins and discs were normal. There was a marked right facial weakness of upper motor neurone type. The remainder of the cranial nerves were normal. The right arm was hypotonic and quite severely weak. The tendon reflexes were increased in the right arm, but were symmetrical in the legs. The abdominal reflexes were present and the plantar reflexes were flexor. Sensation was intact. Blood pressure was 220/140 mm. Hg.

A left carotid arteriogram was performed four days after admission. This showed an irregular filling defect arising mainly from the posterior wall of the internal carotid artery extending from the origin of the artery for approximately $1.5 \mathrm{~cm}$. The anterior and middle cerebral vessels appeared normal in size, shape, and distribution.

Immediately following arteriography the patient hecame stuporose. He now had a dense, flaccid right hemiplegia with a right extensor plantar reflex. He remained barely rousable, and died a week after the arteriogram.

Laboratory investigations (Professor J. N. Cumings) carried out before angiography included examination of the cerebrospinal fluid which was clear and colourless and contained 1 cell per c.mm. and $75 \mathrm{mg}$. per $100 \mathrm{ml}$. of protein; the Pandy test was weakly positive and the colloidal gold curve 0001121100 . The Wassermann reaction was negative in cerebrospinal fluid and blood. The blood urea was $27 \mathrm{mg} . \%$. An electroencephalogram showed an $\alpha$ rhythm at 9-10 cycles per second, which was better distributed on the right than on the left. There was continuous irregular slow-wave activity of medium or high voltage, maximal in the left posterior temporal region.

Necropsy findings (Professor W. Blackwood) The heart showed ventricular dilatation. There was marked atheroma of the coronary arteries. The thoracic aorta was healthy but there was increasing atheroma from above downwards in the abdominal aorta. The right common, internal, and external carotid arteries and the right innominate and subclavian arteries appeared healthy. The left external carotid artery was healthy but in the left internal carotid artery (Fig. 6) there was a large, partly calcified plaque of atheroma affecting its lower $7 \mathrm{~mm}$. and projecting well into the former lumen which had been completely occluded by recent antemortem thrombus. The thrombus extended upwards for $15 \mathrm{~mm}$. from the origin of the artery which was then normal until the intracavernous portion was reached, where slight atheroma was again present. There was more severe atheroma in the intracavernous part of the right internal carotid. The intradural but extracerebral portion of each internal carotid artery showed marked concentric atheromatous narrowing. A large branch of the left middle cerebral artery was occluded by organizing thrombus. Microscopically the lesion at the origin of the 

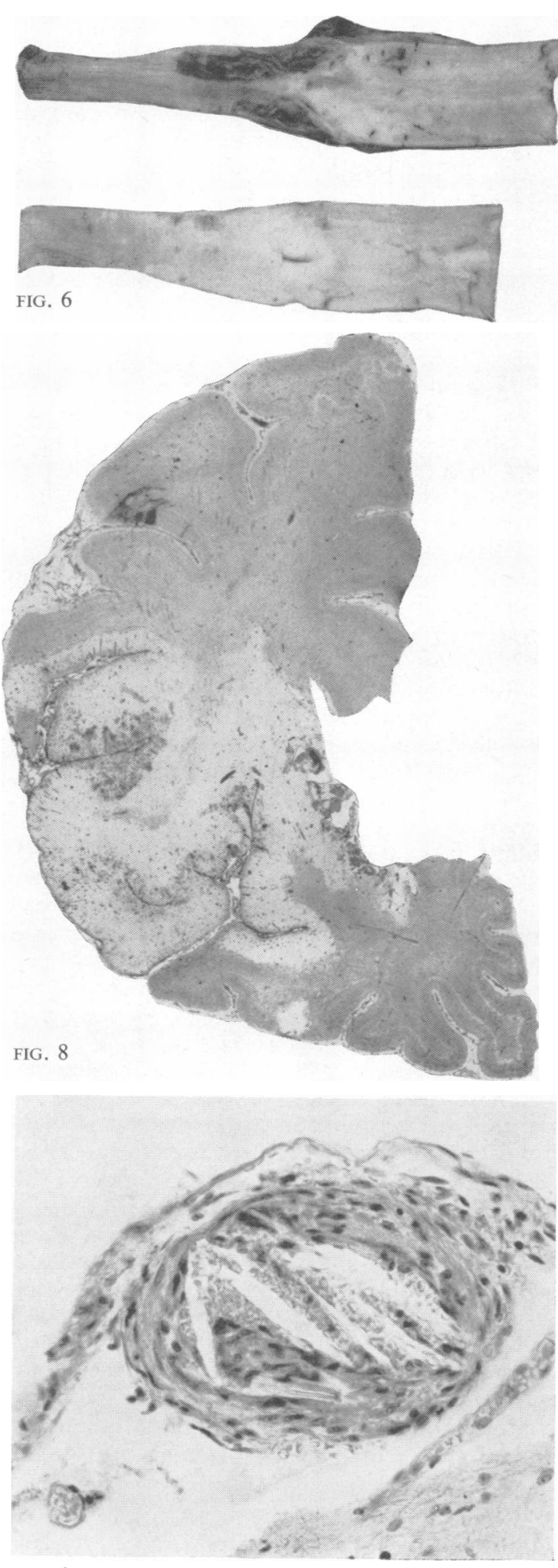

FIG. 10

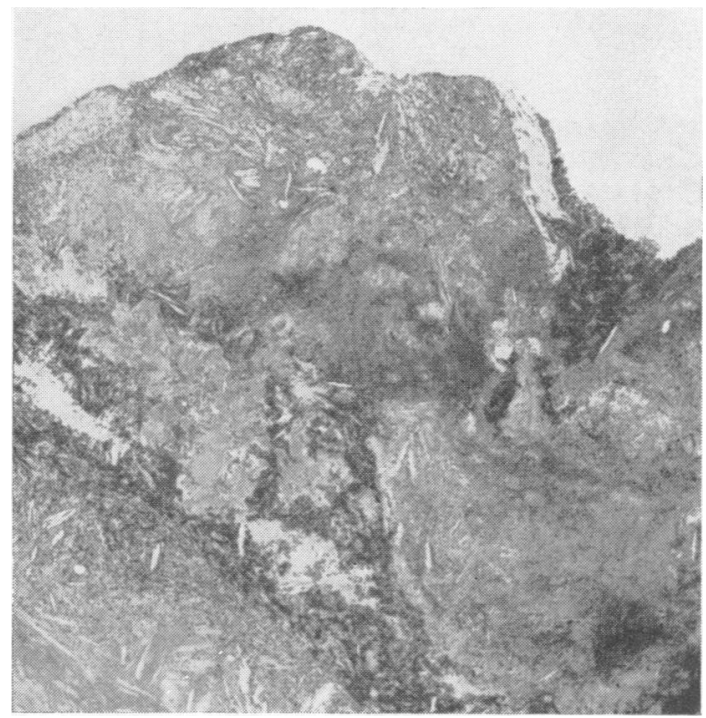

FIG. 7

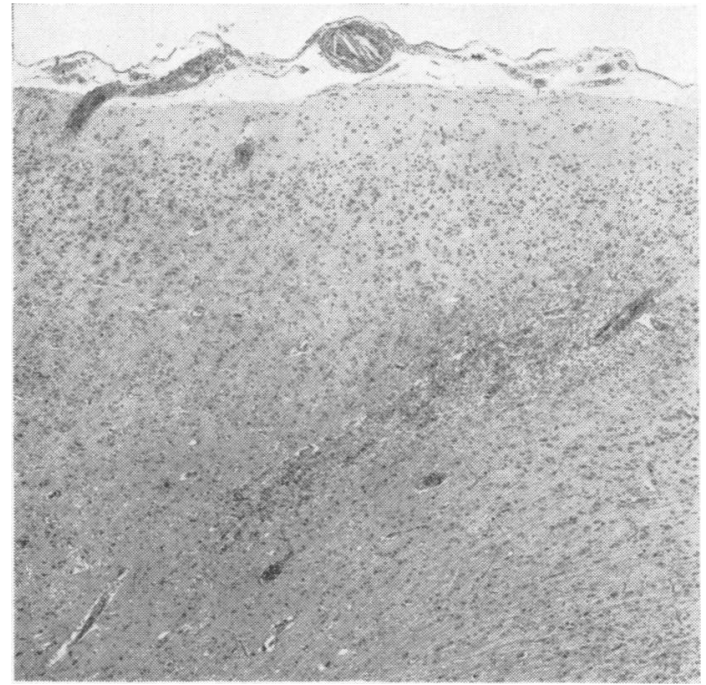

FIG. 9

FIG. 6. Case 2. Origin of the internal carotid artery on the right (above) and left (below).

FIG. 7. Case 2. Section of part of the atheromatous plaque shown in Figure 6. The intima is eroded and numerous cholesterol clefts are seen at the luminal (free) surface of the lesion, and more deeply. H.V.G. $\times 30$.

FIG. 8. Case 2. Coronal section of cerebral hemisphere. In addition to the large pale zone of recent infarction there is a small dark zone of older infarction in the cortex above the main lesion. Nissl $\times 11$.

FIG 9. Case 2. Cerebral cortex. A meningeal artery containing cholesterol clefts overlies a small cortical infarct. H.V.G. $\times 30$.

FIG. 10. Case 2. The abnormal artery from Fig. 9 showing fibroblastic proliferation and giant cell formation. H.V.G. $\times 250$. 
internal carotid showed atheroma with adherent recent intimal thrombus. Of particular interest were several regions close to the luminal surface of the lesion in which there were numerous needle-like clefts identical with those found in the cerebral arteries in case 1 (Fig. 7).

Neuropathological findings The skull and dura were healthy. There was a patch of atheroma at the bifurcation of the left internal carotid artery. No emboli were found in the larger branches of the left middle and anterior cerebral arteries. In the left cerebral hemisphere patches of bluish subcortical discolouration lay in a horseshoe fashion about $2-4 \mathrm{~cm}$. from the lateral fissure. There was no evidence of infarction in the distribution of the anterior and posterior cerebral arteries. Moderate temporal herniation was present on the left side.

Coronal section of the hemispheres showed pathological changes in the distribution of the left middle cerebral artery (Fig. 8). In the upper and posterior part of the convexity of the hemisphere, extending back into the precentral gyrus, the cortex was pale and ill defined with small cavities in the underlying white matter. There was extensive very haemorrhagic infarction involving the region of the left basal ganglia which posteriorly had erupted as actual haemorrhage in the left lateral ventricle.

Microscopical examination revealed small haemorrhagic infarcts in the more posterior parts of the area of distribution of the middle cerebral artery. In the middle and posterior frontal and Rolandic regions and extending also back into the posterior parietal lobe there was an area of ischaemic necrosis involving white and grey matter with severe destruction of nerve cells, dilatation of capillaries and infiltration with polymorphs. At the margins of the lesion there was capillary endothelial hyperplasia and fat granule cells were present. These appearances were compatible with an infarct of about one week's duration. In a large branch of the middle cerebral artery situated in a sulcus at about the middle of the convexity was a mass of organizing thrombus.

In the peripheral parts of the region of supply of the left middle cerebral artery there were numerous scattered small foci of older infarction where the tissue was completely broken down and replaced by fat phagocytes with reactive astrocytes around the periphery of the lesions. In relation to several of these lesions, nearby arterioles in the sulci contained needle-like clefts identical with those in the carotid atheromatous ulcer (Fig. 9). The lumen was frequently partially or completely obstructed by accumulations of giant cells and fibroblasts (Fig. 10). The areas of distribution of the anterior and posterior cerebral arteries were normal.

\section{DISCUSSION}

The striking post-mortem finding in these two cases was the presence of cholesterol crystals in small cerebral arteries and arterioles. In both cases there was severe ulcerative atheroma in the large vessels proximal to the sites of small vessel obstruction: in case 1 in the arch of the aorta and case 2 in the left internal carotid artery. Needle-like clefts (presum- ably the site of cholesterol crystals) were identified at the surface of the intimal lesion in case 2 . Similar findings of cholesterol plugging small arteries and arterioles have been described frequently in the abdominal viscera (Flory, 1945; Schnornagel, 1961) and less often in other organs. Some 25 examples of cholesterol plugging of cerebral vessels have been reported (Meyer, 1947; Winter, 1957; Sayre and Campbell, 1959; Hoye, Teitelbaum, Gore, and Warren, 1959; Gore and Collins, 1960; Sturgill and Netsky, 1963; Soloway and Aronson, 1964). An excellent general review of the subject has recently appeared (Eliot, Kanjuh, and Edwards, 1964). Moderate or severe atheroma of the aorta proximal to the origin of the occluded vessels, usually with ulceration of atheromatous plaques, has been present in all cases in which the appropriate necropsy details are reported.

There is considerable evidence that the cholesterol crystals found in the lumen of small arteries and arterioles arrive there by embolization from proximal atheroma (Gunning, Pickering, Robb-Smith, and Ross Russell, 1964). Histologically, cholesterol crystals are found both in the plugged vessels and in the plaques of atheroma, and a careful chemical analysis by David, Klintworth, Friedberg, and Dillon (1963) has shown that the material making up plugs in the retinal arterioles of their case was identical in composition with that in the atheroma of the carotid artery. It has been suggested, however, that the crystals might arise in situ from local thrombosis or atheroma. There are several strong arguments against this explanation. Arterial thrombosis is common, but intraarterial cholesterol crystals are rarely found. Atheroma is exceedingly uncommon in small arteries and arterioles of the size (approximately $200 \mu$ ) in which cholesterol crystals have been found. Finally, such an explanation does not account for the presence of cholesterol within the lumen of otherwise normal vessels.

The histological response to the presence of cholesterol emboli in small cerebral arteries in the present cases varied. Around some emboli there was no reaction at all (Fig. 4), while multinucleate giant cells, intimal thickening, and fibrosis were found around others (Fig. 5) in varying amounts. Similar changes have been reported previously to occur around cholesterol emboli in the brain and elsewhere both in human disease and also in experimental animals after the injection of cholesterol crystals or of human atheromatous material (Flory, 1945; Snyder and Shapiro, 1961; Otken, 1959). After an injection of a suspension of cholesterol crystals into the ear vein of a rabbit, Snyder and Shapiro (1961) found cholesterol emboli in the 
pulmonary arterioles. Within 24 hours there was a cellular reaction of neutrophils and eosinophils around the embolus. By three days there was a panarteritis with intimal hyperplasia and large numbers of eosinophils; giant cells had appeared. After six days the polymorph response had almost subsided but the giant cells were more numerous. Fibrosis was apparent by the twelfth day. Five months later cholesterol crystals surrounded by fibrous tissue were still present; a lumen was frequently visible at this stage, suggesting that recanalization had occurred. The various appearances around the cholesterol crystals and the morphology of the small infarcts in the present cases suggests that embolism had occurred at different times. Precise determination of the age of the lesions is not possible but the appearances in the vessels are consistent with the duration of the clinical histories.

The true frequency with which cerebral cholesterol embolism occurs is at present uncertain. Only 25 cases have hitherto been described. Fifteen were found in a consecutive series of 6,685 necropsies, a prevalence of $0.2 \%$ (Soloway and Aronson, 1964). Three cases of cholesterol embolism of spinal arterioles are recorded (Périer, Demanet, Henneaux, and Nunès Vincente, 1960; Soloway and Aronson, 1964). On the other hand visceral cholesterol embolism, at one time regarded as a very rare phenomenon, has been found on careful retrospective examination in about 12 to $15 \%$ of cases with severe ulcerative atherosclerosis of the abdominal aorta (Flory, 1945; Thurlbeck and Castleman, 1957; Schnornagel, 1961). The relatively uncommon occurrence of severe ulcerative atheroma of the arch of the aorta is undoubtedly one reason for the small number of reports of cerebral cholesterol embolism; clinical evidence of syphilis in six previously reported cases of cerebral cholesterol embolism is therefore of interest because of the predisposition to atheroma of the aortic arch in this disease. It seems probable that more cases of cerebral cholesterol embolism would be recognized if cholesterol clefts were carefully looked for microscopically in all cases of severe atheroma of the aortic arch and the major arteries in the neck. There is of course no reason to suppose that embolism from atheromatous ulcers is restricted to cholesterol; it is highly likely that other components tooperhaps less histologically distinctive in routine preparations-are dislodged as emboli.

No distinctive clinical syndrome by which cerebral cholesterol embolism may be recognized in life has emerged from the published reports. Arterial hypertension is usual and evidence of arterial disease in the myocardium or extremities is common. But an important clue, not as it happens so far reported in association with cerebral cholesterol embolism, might come from examination of the fundi. Cholesterol embolism of the retina in association with fluctuating visual disturbance is now well recognized (Russell, 1963; David et al., 1963). If retinal emboli were seen at or soon after an episode of neurological deterioration it would be reasonable to suppose that cerebral atheromatous embolism had also occurred. Provided a patient was otherwise fit, arch aortography should be carried out in such circumstances as these, for it is now feasible to prevent further deterioration or recurrence of symptoms by surgical resection of a localized atheromatous lesion if this is single and definitely the source of the emboli.

\section{SUMMARY}

The clinical features and pathological findings in two patients with recurrent cerebral cholesterol embolism are described. In each case there was a fluctuating but progressive neurological disturbance. At necropsy there was severe ulcerative atheroma of a major artery proximal to the sites of the emboli. The diagnosis of cerebral cholesterol embolism should be suspected when retinal atheromatous emboli are observed in patients with fluctuating cerebral symptoms.

The permission of Dr. G. A. Emmerson, Royal West Sussex Hospital, Chichester, and of the physicians and surgeons of the National Hospital, Queen Square, to study their cases is gratefully acknowledged. I am particularly grateful to Professor William Blackwood for his help in the study of the pathological material, to Dr. R. W. Ross Russell for much helpful discussion, and to Mr. J. A. Mills for the photography.

\section{REFERENCES}

David, N. J., Klintworth, G. K., Friedberg, S. J., and Dillon, M. (1963). Fatal atheromatous cerebral embolism associated with bright plaques in retinal arterioles. Neurology (Minneap.), 13, 708-713.

Eliot, R. S., Kanjuh, V. I., and Edwards, J. E. (1964). Atheromatus embolism. Circulation, 30, 611-618.

Fisher, C. M. (1959). Observations of the fundus oculi in transient monocular blindness. Neurology (Minneap.), 2, 333-347.

Flory, C. M. (1945). Arterial occlusions produced by emboli from eroded aortic atheromatous plaques. Amer. J. Path., 21, 549-565.

Gore, I., and Collins, D. P. (1960). Spontaneous atheromatous embolization: review of the literature and a report of sixteen additional cases. Amer. J. clin. Path., 33, 416-426.

Gunning, A. J., Pickering, G. W., Robb-Smith, A. H. T., and Ross Russell, R. (1964). Mural thrombosis of the internal carotid artery and subsequent embolism. Quart. J. Med., 33, 155-195.

Hoye, S. J., Teitelbaum, S., Gore, 1., and Warren, R. (1959). Atheromatous embolization: a factor in peripheral gangrene. New Engl. J. Mie.t., 261, 128-131 
Meyer, W. W. (1947). Cholesterinkrystallembolie kleiner Organarterien und ihre Folgen. Virchows Arch. path. Anat., 314, 616-638.

Otken, L. B. (1959). Experimental production of atheromatous embolization. Arch. Path., 68, 685.

Périer, O., Demanet, J.-C., Henneaux, J., and Nunès Vincente, A. (1960). Existe-t-il un syndrome des artères spinales postérieures? A propos de deux observations anatomocliniques. Rev. neurol., 103, 396-409.

Richardson, E. P. (1961). Progressive multifocal leukoencephalopathy. New Engl. J. Med., 265, 815-823.

Russell, R. W. R. (1961). Observations on the retinal blood vessels in monocular blindness. Lancet, 2, 1422-1428.

(1963). Atheromatous retinal embolism. Lancet, 2, 1354-1356.

Sayre, G. P., and Campbell, D. C. (1959). Multiple peripheral emboli in atherosclerosis of the aorta. Arch. intern. Med., 103, 799-806.

Schornagel, H. E. (1961). Emboli of cholesterol crystals. J. Path. Bact., 81, 119-122.

Snyder, H. E., and Shapiro, J. L. (1961). A correlative study of atheromatous embolism in human beings and experimental animals. Surgery, 49, 195-204.

Soloway, H. B., and Aronson, S. M. (1964). Atheromatous emboli to central nervous system. Arch. Neurol. (Chic.), 11, 657-667.

Sturgill, B. C., and Netsky, M. G. (1963). Cerebral infarction by atheromatous emboli. Arch. Path., 76, 189-196.

Thurlbeck, W. M., and Castleman, B. (1957). Atheromatous emboli to the kidneys after aortic surgery. New Engl. J. Med., 257, 442-447.

Winter, W. J. (1957). Atheromatous emboli: a cause of cerebral infarction. Arch. Path., 64, 137-142. 